\title{
Allogeneic Tumor Cell Vaccine
}

National Cancer Institute

\section{Source}

National Cancer Institute. Allogeneic Tumor Cell Vaccine. NCI Thesaurus. Code C1983.

A vaccine composed of tumor cells isolated from the tumor of one patient, killed and processed, and administered to another patient to stimulate cytotoxic immune responses to a similar tumor cell type. The cells found in this type of whole-cell vaccine express many cell-surface tumor-associated antigens. This vaccine is frequently administered with an adjuvant immunostimulant. (NCI04) 